\title{
A Review of Tidal Power Potential in Kenya Aron Oronyi Ohuru
}

\author{
Department of Electrical Engineering, Technical University of Mombasa, P.O. Box 90420 - 80100, \\ Mombasa, Kenya
}

Author's email: oronyirom@gmail.com

\begin{abstract}
7 he world is experiencing a dynamic shift in terms of energy production, with nations focusing more on renewable sources of energy. This is because renewable energy sources are eco-friendly, reserves of fossil fuels around the world are getting depleted, and unstable market prices of these fossil fuels. Here in Kenya, the revolution has been felt, especially with heavy investment in geothermal and wind power. Since hydroelectric, geothermal and wind power account for more than $70 \%$ of energy consumption in Kenya, it is evident that Kenya is taking strides in the correct direction. However, tidal energy is still left behind in this foray, despite its large potential due to the presence of Kenya's coastline measuring $640 \mathrm{~km}$ long, and most notably, the predictability of this tidal energy. Due to the fact that tidal energy is directly related to the gravitational relationship between the earth and the moon, which is predictable, tidal energy can really help in terms of reduction of pressure and dependence on the hydro power generating seven forks scheme in Kenya. If well synchronized, tidal energy can help alleviate the chronic power rationing that occurs during the dry season in Kenya. By studying work done in other countries, large scale production of electric power from tidal energy can be achieved.
\end{abstract}

Key Words: Water head, Tidal stream, Renewable energy, Grid synchronization

\section{Introduction}

There has been a surge in electric power intake in Kenya, especially due to the Rural Electrification Project and the increase in manufacturing companies, implying a growth in the manufacturing sector. This upsurge is expected to grow, due to the projected growth in manufacturing sector, spurred on by the Kenya Government Big Four Agenda development strategy. Kenya is expected to have a demand of 15,000 MW by the year 2030 (Table 1), from a demand of 1,802 MW in 2018 (Otuki, 2018). The foray of the Kenya Government into wind and geothermal energy plans to try and cover this wide gap, with plans for a nuclear reactor underway. Kenya however, has another source of electrical energy idling, one with huge potential that is ignored.

Table 1. Projected generation capacity and demand of electricity in Kenya (Otuki, 2018)

\begin{tabular}{|l|l|l|}
\hline Year & Demand (MW) & Capacity \\
\hline 2013 & 1,191 & 1,600 \\
\hline 2018 & 1,802 & 2,351 \\
\hline 2030 & 15,000 & 19,200 \\
\hline
\end{tabular}

With the advent of more efficient turbines, tidal energy can be harvested along the Kenya coast, hence reducing the strain on the current power sources, and if well synchronized, can help ease the power rationing problems that are experienced during the dry season. Since oceans cover slightly more than $70 \%$ of the earth's surface, they can be used to provide vast amounts of energy, which can be converted to electricity and consumed by members of the society.

With the emergence of global warming, there has been a general trend in countries avoiding sources that tend to release harmful gasses into the environment and there has been a leaning toward clean energy, examples being solar, wind and tidal energy. Kenya can jump into this bandwagon and be among the leading countries in tidal power production. Energy diversification also plays as a huge advantage, by reducing reliance on just a few established sources and expanding our range of options when it comes to energy sources.

Tidal energy, though not as popular as its counterparts such as wind and solar, is a promising source. Apart from the fact that it does not emit any 
greenhouse gasses, tidal energy has the added advantage of not being affected by climate change, that is, it does not depend on the weather patterns, due to the fact that tides are influenced by the gravitation force between the earth, the moon and the sun. The same fact also gives it another major advantage over most energy sources. Since tidal energy is reliant on the gravitational force between the earth, sun and moon, and this phenomenon is well known and predictable. This could make tidal energy very predictable, hence easy to manage and plan for (Rosli \& Dimla, 2018).

\section{Tidal Energy Harvesting Methods}

Tidal energy can basically be harvested in two major ways, and several variations of these methods exist. These include the use of tidal barrages and tidal stream generators. These methods have been researched on and are the major methods currently being used to harvest tidal energy. For example, the world's largest tidal energy plant, the Shiwa Lake Tidal Power Station, uses a tidal barrage to produce about $254 \mathrm{MW}$ (Rosli \& Dimla, 2018).

\section{Tidal Barrages}

Tidal barrages use potential energy due to difference of water head during low and high tides. A dam/wall/barrage is placed at the entrance to a tidal estuary. As water floods towards the coast during the high tide, it flows through the barrage, producing the torque required to rotate a turbine hence producing electricity. During low tide, as water migrates to the ocean, it passes through the barrage again, hence rotating the turbine and producing electricity (Rosli \& Dimla, 2018).

Currently, tidal barrages account for $90 \%$ of the world's tidal energy production. This form of energy generation can be very useful, especially in creeks along the Kenya coast, such as Mida, Kilifi, Tudor and Mtwapa creeks. However, that tends to be their limitation, since barrages can only be used around enclosed areas. Apart from this, there are major infrastructure considerations to be taken into consideration, being that the barrage has to be built as well as the potential to harm flora and fauna around the area where the barrage is built.

\section{Tidal Current Stream Generators}

Tidal current stream generators are also used, and resemble wind turbines. These turbines are placed in water and are rotated when water rushes to the coast during change of tides, producing electricity. The main advantage of underwater turbines is that they do not have to run as fast as air turbines, due to the fact that water is about 839 times denser than air, hence compensates by far the speed factor (ARahman et al., 2010). They however, do require strong rigging in order to hold them in place and that can withstand strong currents (Da \& Khaligh, 2009). This technology is already available, as it closely resembles the same technology used in holding offshore mining rigs. However, their capacity is not so large. They may also affect marine life due to the fact that they are blades rotating in water. Possible locations for tidal stream plants along the Kenya coast include Lamu and Diani, due to the existence of high tidal stream speeds.

According to DeGunther, (2009), tidal energy is associated with various advantages. Tides are renewable, sustainable and predictable. Very large differential between high and low tides allows for production of tidal areas. Tidal power generators do not produce pollutant gasses. The fact that tidal barrage generators are easy to maintain whereas turbines are totally beneath the earth's surface hence do not interfere with the beauty of the environment. Since they only depend on gravitational force of the earth, sun and moon, tidal tides are not affected by climatic factors such as drought or change in wind patterns.

Further, Degunther, (2009) has also pointed out the disadvantages associated with tidal energy including being capital intensive with up-front costs being relatively high. Tidal energy generation is associated with young immature technology since little research has been done on turbines with difficulty in installation. Installed tidal turbines may affect the marine ecosystems especially if marine life gets lodged in the turbines. In case of failure, especially in barrages, flooding may occur in the surrounding areas.

\section{Mechanical power transformation}

\section{Betz Limit}

For most fluid-based energy production, units, several factors have to be taken into consideration, in this case, Betz law, which states that no turbine can capture more than 16/27 of the kinetic energy of wind (Afework, 2018). This is also applicable in underwater turbines as used in tidal current stream 
generators. Practical turbines achieve up to $75 \%$ $80 \%$ of the Betz limit (Onundo \& Mwema, 2016).

Mechanical Losses in Gears

Losses in gear boxes of the turbines also have to be taken into account when dealing with energy systems. Most gear boxes have efficiencies of up to $90 \%$ considered to be quite substantial.

\section{Conversion of Mechanical Power to Electrical Power}

According to Da \& Khaligh (2009), the following equation is applied in the conversion of mechanical power to electrical power:

$p=\frac{1}{2} \rho A C_{\mathrm{p}}(\lambda, \beta) \mathrm{v}^{3}$

where

$p=$ power captured from turbine, $\rho=$ density of water, $A$ is the swept area of the turbine, $C P$ is the power coefficient of the turbine, which is a function of tip speed ratio (TSR, $\lambda$ ) and pitch angle $(\beta), v$ is the wind/water current speed $(\mathrm{m} / \mathrm{s})$.

Tip speed ratio can be calculated as $\omega_{\mathrm{m}} \mathrm{R} / \mathrm{v}$ where $\omega_{\mathrm{m}}$ is the mechanical rotational speed of the turbine.

\section{Possible Solutions to Efficiency Problems}

Maximum Power Point Tracking

Use of maximum power point tracking may prove useful in making more efficient tidal turbine systems. This technique uses changing of certain parameters with change in ambient conditions in order to get maximum output from the turbines even in conditions that may not be quite ideal. This requires use of models and simulation, which are beyond the scope of this paper. However, it can be stated that some of the parameters that can be varied include stator current and turbine angle (Da \& Khaligh, 2009).

\section{Potential Resource Assessment}

The resources can be assessed and reviewed based on outcomes derived from real time data collection and simulation (Fig. 1). Perhaps a useful tool to be put in use is the DELFT 3D, a tool that simulates 2dimensional (in either the horizontal or a vertical plane) and 3-dimensional flow, sediment transport and morphology, waves, water quality and ecology and is capable of handling the interactions between these processes.

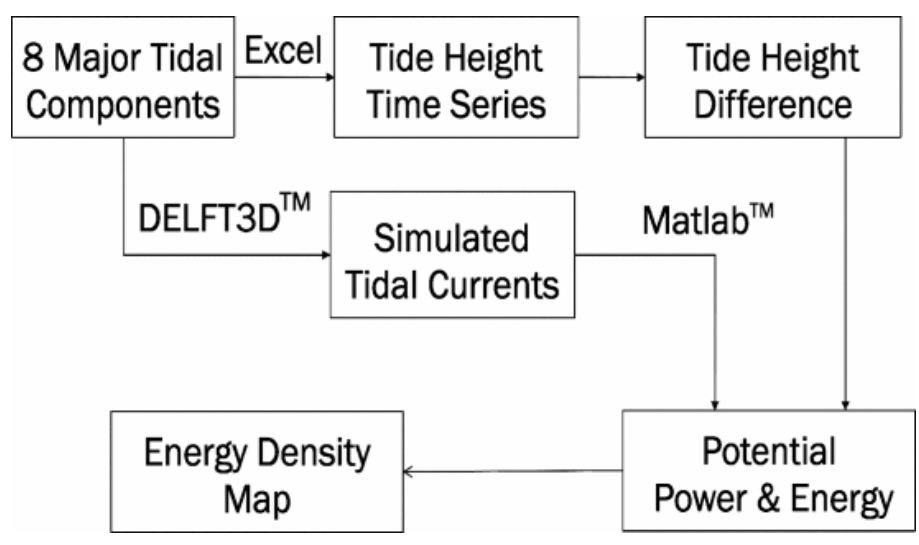

Figure 1. Block diagram for resource management (Abundo et al., 2011)

By using the above process (Fig. 1), energy density can be mapped hence gauge the potential energy that can be generated from specific sites. This will help to transform the concept of tidal energy from just abstract figures into a workable plan. With figures, it would be easier to get both funding institutions and the general public on board, and help chart a course to making tidal energy a reality.

\section{Conclusion}

This paper provides a quick overview of power generation using tidal energy and the appropriate sites for possible implementation and points out advantages, disadvantages and possible solutions to problems that may be faced during implementation of tidal power generation in Kenya as well as elsewhere. This gives a baseline, arguing a case for the advancement of tidal power in Kenya and elsewhere.

\section{References}

Abundo, M.L.S., Nerves, A.C., Ang, M.R.C.O., Paringit, E.C., Bernardo, L.P.C. \& Villanoy, C.L. (2011). Energy potential metric for rapid macro-level resource assessment of tidal instream energy in the Philippines. 10 th International Conference on Environment and Electrical Engineering. Rome, Italy: IEEE: 1-4

ARahman, M.L., Oka, S, \& Shirai, Y. (2010). Hybrid power generation system using offshore wind turbine and tidal turbine for power fluctuation compensation. IEEE Transactions On Sustainable Energy: 92-98 
Fework, B., Hanania, B.J., Stenhouse, K. \& Donev, J. (2018). Energy Education/Betz Limit. Accessed on March $15^{\text {th }}$ 2019, from University of Caglary: https://energyeducation.ca/encyclopedia/Be tz_limit

Da, Y. \& Khaligh, A. (2009). Hybrid offshore wind and tidal turbine energy harvesting system with independently controlled rectifiers. IEEE energy: 4557-4582

DeGunther, R. (2009). Alternative Energy for Dummies. Hoboken, NJ: Wiley Publishing, Inc.

Rosli, R. \& Dimla, E. (2018). A review of tidal current energy resource assessment:. $20185^{\text {th }}$ International Conference on Renewable Energy: Generation and Applications (ICREGA): 34 - 40

Otuki, N. (2018). Business Daily. Accessed on March 15th 2019, from https://www.businessdailyafrica.com/econo my/Electricity-demand--crosses-1-800MWmark/3946234-4645308-ur8eup/index.html

Onundo, L.P. \& Mwema, W.N. (2016). Estimating marine tidal power in Kenya. International Journal of Energy and Environmental Engineering: 1013-1017 